\title{
ChemComm
}

\section{Conjugated microporous polytriphenylamine networks $\dagger$}

Cite this: Chem. Commun., 2014

50,8002

Yaozu Liao, ${ }^{a}$ Jens Weber ${ }^{b}$ and Charl F. J. Faul*a

Received 23rd April 2014

Accepted 4th June 2014

DOI: $10.1039 / \mathrm{c} 4 \mathrm{cc} 03026 \mathrm{e}$

www.rsc.org/chemcomm

Conjugated microporous polytriphenylamine networks with surface areas of $530 \mathrm{~m}^{2} \mathrm{~g}^{-1}$ were synthesized via Buchwald-Hartwig coupling, resulting in high $\mathrm{CO}_{2}$ uptake (up to 6.5 wt\%) and $\mathrm{CO}_{2}-\mathrm{N}_{2}$ selectivity (75) at 1 bar and $303 \mathrm{~K}$.

Conjugated microporous polymers (CMPs) with intrinsic properties including small pore sizes $(<2 \mathrm{~nm})$, large specific surface areas $\left(>6000 \mathrm{~m}^{2} \mathrm{~g}^{-1}\right),{ }^{1}$ high chemical stability, low skeleton density and reversible redox properties exhibit great promise for gas storage, separation, sensing, catalysis and battery applications. ${ }^{2}$ Versatile CMPs have been obtained readily through template-free chemical processes by careful selection of building blocks and, commonly, suitable $\mathrm{C}-\mathrm{C}$ or $\mathrm{C}-\mathrm{N}$ coupling reactions, which showed efficient preparation and high flexibility in the molecular design. Typically, Suzuki, ${ }^{3}$ Sonogashira-Hagihara ${ }^{4}$ and Yamamoto coupling, ${ }^{5}$ Schiffbase chemistry, ${ }^{6}$ cyclotrimerization ${ }^{7}$ and oxidative polymerization ${ }^{8}$ reactions have been used to synthesize CMPs. Previous studies demonstrated that control over average micropore size, surface area, and gas uptake of the CMPs was enabled by alternating the strut lengths, rigidities, and functionalities of the building blocks. ${ }^{2}$

Buchwald-Hartwig (BH) coupling is utilized in organic synthesis for the generation of $\mathrm{C}-\mathrm{N}$ bonds via the palladium-catalysed crosscoupling of amines with aryl halides. The BH coupling approach allows for expansion of the repertoire of possible $\mathrm{C}-\mathrm{N}$ bond formation through the facile synthesis of aromatic amines. This useful method also provides a simple route to nitrogen-containing redox-active systems, as shown in recent work ${ }^{9}$ from our laboratories on the synthesis of well-defined symmetrical oligo(aniline)s, OANIs. It is noteworthy that $\mathrm{BH}$ coupling has rarely been used for CMP preparation..$^{10}$

Here we report the synthesis of conjugated microporous polytriphenylamine (PTPA) networks with a surface area up to

\footnotetext{
${ }^{a}$ School of Chemistry, University of Bristol, Bristol, England BS8 1TS, UK. E-mail: charl.faul@bristol.ac.uk

${ }^{b}$ Hochschule Zittau/Görlitz (University of Applied Science), Department of Chemistry, Theodor-Körner-Allee 16, D-02763 Zittau, Germany

$\dagger$ Electronic supplementary information (ESI) available: Studies on the synthesis, characterization, morphology, and gas adsorption-desorption of the PTPAs. See DOI: $10.1039 / \mathrm{c} 4 \mathrm{cc} 03026 \mathrm{e}$
}

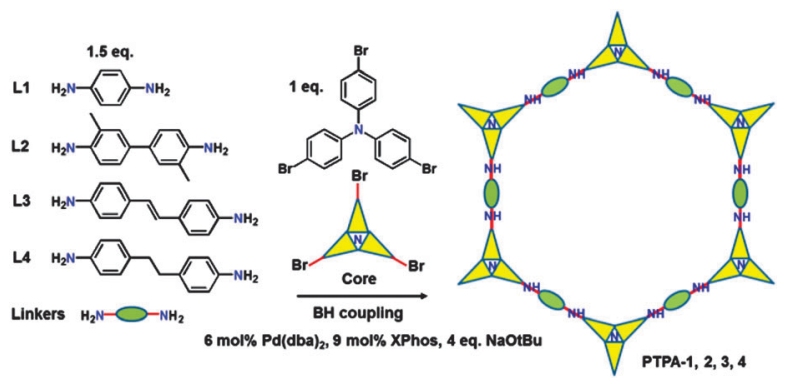

Scheme 1 Synthetic route to conjugated microporous PTPAs.

$530 \mathrm{~m}^{2} \mathrm{~g}^{-1}$ using BH coupling (Scheme 1). Our target was to design and synthesise intrinsically microporous materials based on conjugated polymer networks from a triphenylamine bromide core and selected aryl amine linkers. This approach, exploiting careful choice of strut lengths, rigidities of the linkers and additional included functionalities, would allow formation of nitrogen-containing CMPs with fine-tuned porosities and $\mathrm{CO}_{2}$ adsorption/separation capabilities.

Verification of this approach was achieved by $\mathrm{BH}$ crosscoupling of aniline with tris(4-bromophenyl)amine. This resulted in $\mathrm{C}-\mathrm{N}$ bond formation, affording the fully reduced molecular analogue of the PTPAs, $4,4^{\prime}, 4^{\prime \prime}$-tris(phenylamino)triphenylamine (analogous to the leucoemeraldine base structure found for OANIs, see ESI, $\uparrow$ Scheme S1). Once verified, BH coupling of diamine species afforded black, blue, brown, and yellow insoluble PTPA-1, 2, 3, 4 powders (Fig. S1, ESI $\dagger$ ) with yields of $65-80 \%$. The chemical structures of the PTPAs were confirmed by Fourier transform infrared (FT-IR) and solid-state ${ }^{13} \mathrm{C}$ cross-polarization magic angle spinning nuclear magnetic resonance (CP/MAS NMR) investigations. Bands of the primary amine group of the linkers at 3470 and $3420\left(-\mathrm{NH}_{2}\right.$ stretching $)$ and $1650 \mathrm{~cm}^{-1}\left(-\mathrm{NH}_{2}\right.$ deformation) as well as the aromatic $\mathrm{C}-\mathrm{Br}$ groups of the tris(4-bromophenylamine) at $1178 \mathrm{~cm}^{-1}$ (aromatic $\mathrm{C}-\mathrm{Br}$ stretching) are absent or strongly attenuated in the spectra of the PTPAs (Fig. S2, ESI $\uparrow$ ). The distinct quinoid (Q) and benzenoid (B) bands at 1598 and $1498 \mathrm{~cm}^{-1}$ as well as the aryl C-H band at $820 \mathrm{~cm}^{-1}$ are present in the spectra of 


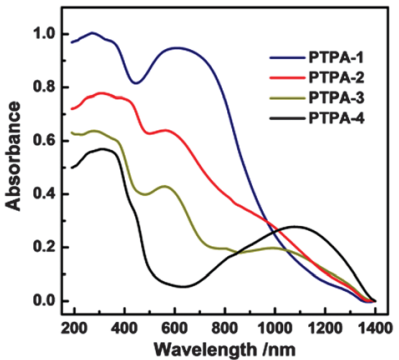

Fig. 1 Solid-state UV/Vis-NIR spectra of PTPAs.

the resulting materials. Solid-state ${ }^{13} \mathrm{C} \mathrm{CP} / \mathrm{MAS}$ NMR spectra of all polymers showed three main resonances at $\sim 141, \sim 127$ and $\sim 118 \mathrm{ppm}$, originating from the aryl carbons of both the starting materials (Fig. S3, ESI $\dagger$ ). Three additional resonances at 17, 116 and $35 \mathrm{ppm}$ are attributed to the methyl, alkenyl and methylene groups of PTPA-2, 3 and 4, respectively. The ultra-violet/visible near infrared (UV/Vis-NIR) spectra of fully conjugated PTPA-1, PTPA-2, and PTPA-3 exhibited two peaks at 380 and $600 \mathrm{~nm}$, typically attributed to the $\pi-\pi^{*}$ transition of benzenoid and quinoid rings (Fig. 1), respectively, as confirmed by recent calculations. ${ }^{9}$ Specifically, PTPA-3 displayed a broad peak around $1100 \mathrm{~nm}$, attributed to the electron and hole migration found in trans-stilbene. ${ }^{11}$ These results confirm the creation of extended conjugated PTPA networks with amine linkages.

As expected, PTPAs displayed amorphous structures, as determined by powder X-ray diffraction (XRD) measurements (broad peaks at $2 \theta=\sim 12.2^{\circ}$, Fig. S4, ESI $\dagger$ ). No $\pi$-stacking was evident from these investigations. Scanning electron microscope (SEM) images showed the morphologies of PTPAs consisting of aggregated nanoparticles with diameters of 200-500 nm (Fig. 2). This leads to some outer surface area (large meso- and macropores due to interstitial voids), which is highest for PTPA-2 and PTPA-3 as evidenced by cryogenic gas adsorption (see below). The transmission electron microscope (TEM) images indicate the microporous structures of the PTPA nanoparticles (see Fig. S5, ESI $\dagger$ ), which are typically found in amorphous CMPs. The materials are thermally stable in $\mathrm{N}_{2}$ up to $500{ }^{\circ} \mathrm{C}$, as revealed by thermal gravimetric analysis (TGA) (see Fig. S6, ESI $\dagger$ ). In particular, for PTPA-3 and PTPA-4, $\sim 60 \mathrm{wt} \%$ remained after heating to $1000{ }^{\circ} \mathrm{C}$.

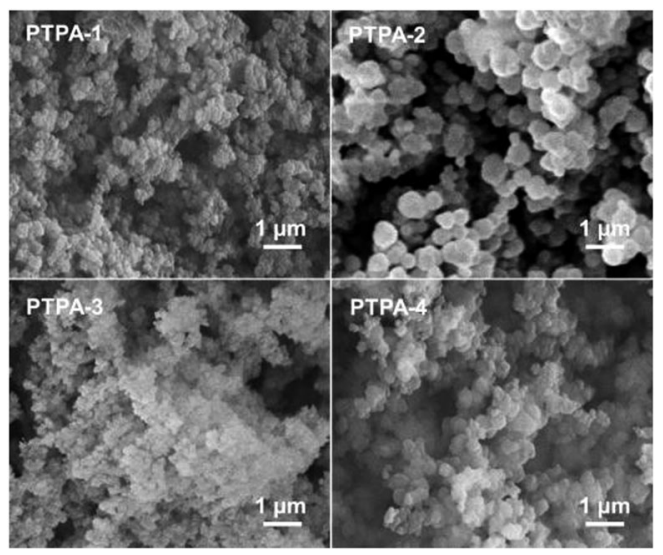

Fig. 2 SEM images of prepared PTPAs.
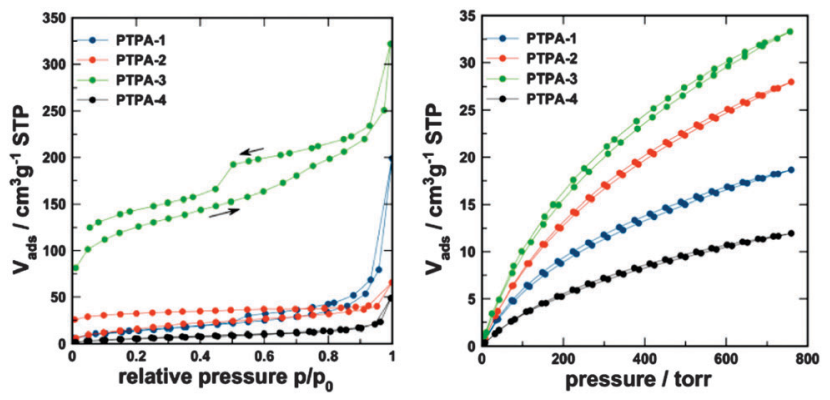

Fig. 3 (left) $\mathrm{N}_{2}$ adsorption-desorption isotherms (77.4 K) and (right) $\mathrm{CO}_{2}$ adsorption-desorption isotherm at $273 \mathrm{~K}$.

The excellent thermal stability of PTPAs is ascribed to the nature of their cross-linked networks.

The porosity parameters of the polymers were initially studied by gas adsorption analysis using nitrogen as the adsorbate. Nitrogen adsorption-desorption isotherms of PTPAs measured at $77.4 \mathrm{~K}$ are shown in Fig. 3. All materials showed some outer surface area, most likely originating from interparticulate porosity associated with the meso- and macrostructures of the samples and interparticular voids. This was evidenced by the steep increase of $\mathrm{N}_{2}$ uptake at relative pressure above 0.9 observed for all materials. It is plausible to expect that precipitation of the growing polymer networks is responsible for the formation of observed macro/mesoporosity.

PTPA-4 does not show any other signs of porosity and consequently shows the lowest $\mathrm{N}_{2}$ uptake. In contrast, PTPA- 1 does show some broadly distributed mesoporosity in conjunction with macroporosity, as derived from the hysteresis between the adsorption and desorption curves, which close around $p / p_{0} \sim 0.45$. PTPA-2 and PTPA-3 show a low-pressure hysteresis (the isotherm curves do not close even at very low $p / p_{0}$ ), which is often observed for microporous polymers. ${ }^{12}$ The hysteresis could result from restricted access of the adsorbate to the some of the micropores of the material, especially to those that are blocked by narrow openings. It has been suggested that additional methods such as $\mathrm{CO}_{2}$ adsorption should be used for micropore analysis (see below). ${ }^{13}$ PTPA-3 shows the highest apparent Brunauer-Emmett-Teller (BET) surface areas (adsorption branch: $450 \mathrm{~m}^{2} \mathrm{~g}^{-1}$; desorption branch: $530 \mathrm{~m}^{2} \mathrm{~g}^{-1}$, see Table 1). Further studies analysing the gas separation potential of this material in more detail is currently under way. PTPA-3 seems to also feature some ill-defined mesoporosity, indicated by the step of the desorption isotherm at the characteristic $p / p_{0}$ of 0.45 (emptying of ink-bottle mesopores by cavitation). PTPA-2, in contrast, does not show signs of mesoporosity based on $\mathrm{N}_{2}$ analysis. The specific pore volumes and surface areas of the PTPA materials are moderate in comparison to other CMPs. However, the combination of micro-, meso- and macroporosity (especially for the PTPA-3 with a determined pore volume of $0.36 \mathrm{~cm}^{3} \mathrm{~g}^{-1}$ ) is of interest for applications that require good mass transfer through so-called transport pores.

$\mathrm{CO}_{2}$ adsorption was measured for all PTPA materials at $273 \mathrm{~K}$ (see Fig. 3) to gain further information on the microporosity. ${ }^{14}$ All materials showed significant $\mathrm{CO}_{2}$ uptake. The highest uptake was found for PTPA-3 (6.5 wt\%), followed by PTPA-2 (5.5 wt\%), 
Table 1 Porosity parameters and $\mathrm{CO}_{2}$ separation properties of the microporous PTPAs

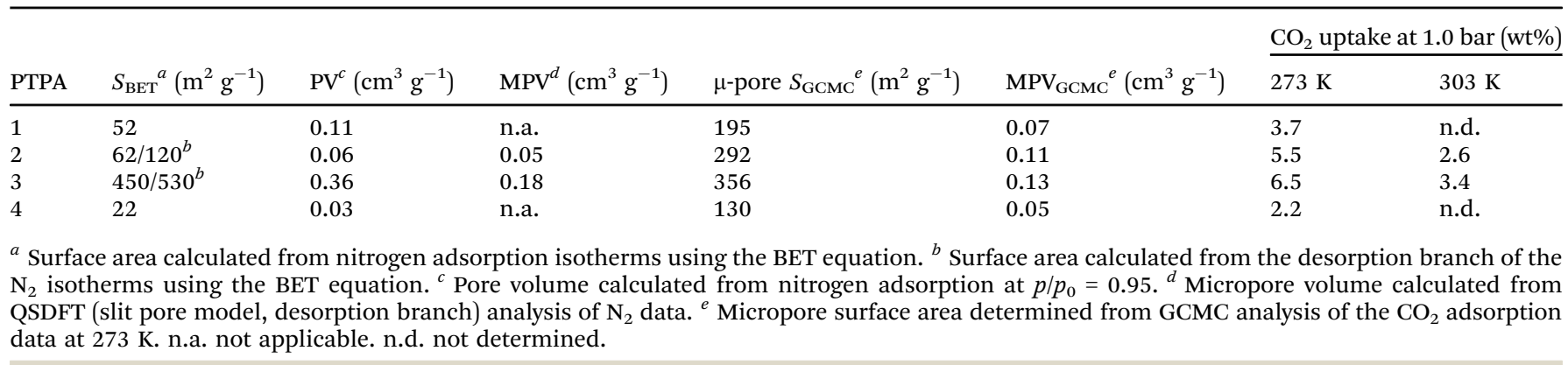

and PTPA-1 and PTPA-4 (uptake $<4$ wt $\%$ ). The isotherms showed only weak hysteresis and were analysed using the commercialized Grand-canonical Monte-Carlo (GCMC), methodology to extract porosity information (see Table 1 ). ${ }^{15}$ All materials show similar broad pore size distributions, which is in line with their amorphous nature. The main fraction of pores have sizes between 0.5 and $1 \mathrm{~nm}$ (Fig. S7, ESI $\dagger$ ).

Generally, PTPAs prepared from monomers containing longer and more rigid struts should show higher apparent specific surface areas if no interdigitating structures are observed. Shorter linkers might lead to compact structures of low porosity. However, the monomer geometry alone is not decisive in determining final porosity, as the reaction conditions, choice of solvents and solubility of the forming polymeric network phase all contribute to the physical properties of the final CMPs. It is nevertheless of worth to discuss the observed porosities with regard to the monomer geometry and rigidity, allowing comparison and conclusions to be drawn for the present systems. The use of the stilbene monomer (L3), which is significantly more rigid compared with its ethylene-bridged counterpart L4, results in the formation of significant microporosity. Interestingly, the very rigid (but shorter) $p$-phenylenediamine (L1) yields a moderately microporous material. The low microporosity could result from the formation of a more dense structure (PTPA-1), i.e. the conjugated segments are less separated and might adhere to each other, favouring pore closure. The methyl-decorated biphenylene-based linker L2 yields a network of considerable microporosity. The strategy to enhance the free volume of, for example, membrane polymers using such methyl-decorated monomers is well known, ${ }^{16}$ and is effective here as well. In the investigated systems monomer molecular structures do impact on the observed porosity, thus following commonly known trends. It also shows that our chosen platform is modular and that porosities could be tuned to reach higher values through further exploration and optimization of the reaction conditions.

The presence of fairly small pores with a uniform distribution of polar amine units is expected to result in favourable interactions between specific adsorbate molecules and the polymeric adsorbent. We analysed the potential of PTPA-3 for gas separation, exemplified by the $\mathrm{CO}_{2}-\mathrm{N}_{2}$ gas pair. The separation of $\mathrm{CO}_{2}$ from, for example, flue gas (post-combustion) is of current interest with regard to the capture of $\mathrm{CO}_{2}$ for environmental (greenhouse gas) or economic reasons $\left(\mathrm{CO}_{2}\right.$ as alternative feedstock for new polymers). There are various other applications, such as cryogenic spray-freezing and food preservation that would benefit from $\mathrm{CO}_{2}$ capture. $\mathrm{CO}_{2}$ adsorption on PTPA-3 at $30{ }^{\circ} \mathrm{C}(303 \mathrm{~K})$ was $0.765 \mathrm{mmol} \mathrm{g}^{-1}$ (3.4 wt\% at $\left.1.0 \mathrm{bar}\right)$, lower compared with some standard materials (zeolites, activated carbon). The $\mathrm{N}_{2}$ adsorption on PTPA-3 at $30{ }^{\circ} \mathrm{C}$ was found to be $0.022 \mathrm{mmol} \mathrm{g}^{-1}$ at $1.0 \mathrm{bar}$, resulting in an equilibrium selectivity of $\alpha\left(\mathrm{CO}_{2} / \mathrm{N}_{2}\right)_{\text {eq }} \sim 35$. Further analysis was performed by calculating the IAST selectivity at $30{ }^{\circ} \mathrm{C}$ based on the assumption of a gas composition of $15 \%(\mathrm{v} / \mathrm{v}) \mathrm{CO}_{2}$ balanced with $\mathrm{N}_{2}$. The necessary description of the isotherm was achieved by fitting the experimental data points by either a simple Langmuir $\left(\mathrm{N}_{2}\right)$ or a dual-site Langmuir fit $\left(\mathrm{CO}_{2}\right)$. It should however be noted that the $\mathrm{CO}_{2}$ data could also be described very well by a simple Langmuir fit (see Fig. S8, ESI $\dagger$ ). The IAST selectivity of $\mathrm{CO}_{2}$ over $\mathrm{N}_{2}$ is calculated to be 75 at ambient pressure $\left(1.0\right.$ bar, $\left.30{ }^{\circ} \mathrm{C}\right)$. This value compares very favourably with most reported results for microporous organic polymers, usually with selectivities in the range 20 to $50 .{ }^{17}$ The predicted adsorption isotherms from the gas mixture are shown in Fig. 4.

The fact that the $\mathrm{CO}_{2}$ adsorption isotherm could also be represented by a simple Langmuir approach indicates that the surface area of PTPA-3 is very homogenous. This is indeed supported by first estimation of the isosteric heat of adsorption $q_{\text {st }}$ based on the $\mathrm{CO}_{2}$ isotherms measured at 273 and $303 \mathrm{~K}$. The $q_{\text {st }}$ remained almost constant over the whole coverage range (values between 27 and $28 \mathrm{~kJ} \mathrm{~mol}^{-1}$ ) indicating a very stable operation regime. The $q_{\text {st }}$ values are somewhat higher than values commonly found for activated carbons or other polymers, but low enough for adsorbent regeneration without too high an energetic penalty.

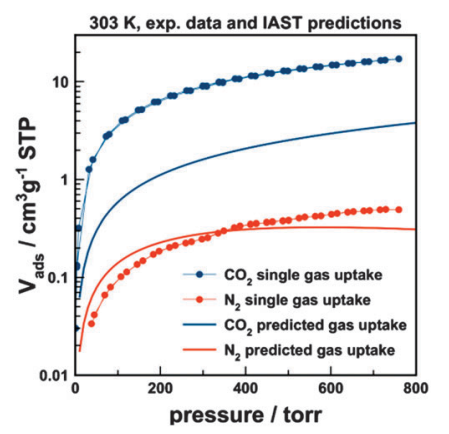

Fig. $4 \mathrm{CO}_{2}$ and $\mathrm{N}_{2}$ adsorption-desorption isotherms (single gas) for PTPA-3 at $303 \mathrm{~K}$ (symbol + line) with predicted adsorption isotherms (line only) from a $0.15 / 0.85 \mathrm{v} / \mathrm{v}$ gas mixture of $\mathrm{CO}_{2}$ and $\mathrm{N}_{2}$ at $303 \mathrm{~K}$ (based on IAST methodology). 
In summary, we have successfully synthesized a series of conjugated microporous polytriphenylamine (PTPAs) based on a triphenylamine core motif using Buchwald-Hartwig (BH) crosscoupling. The BET surface area of these conjugated microporous polymers is up to $530 \mathrm{~m}^{2} \mathrm{~g}^{-1}$. Owing to the microporosity and the homogenously electron-rich and polar pore surface, they exhibit high $\mathrm{CO}_{2}$ uptakes of up to $6.5 \mathrm{wt} \%$ and good $\mathrm{CO}_{2}-\mathrm{N}_{2}$ adsorption ideal selectivities of up to 75 at $303 \mathrm{~K}$ and 1.0 bar. The overall porosity and the corresponding gas adsorption properties strongly depend on the building block size, molecular architectures and functionalities. $\mathrm{BH}$ coupling presents a promising approach for large-scale manufacturing of conjugated microporous polymers and provides a high conversion of functional monomers used. Postsynthesis treatment of the tertiary and secondary amines resulting in permanent quarterisation and careful choice of corresponding counterions may enable tuning of gas uptake and selectivity. Continued investigation into the design, synthesis and characterisation of related materials is on-going in our laboratories.

We are grateful to the European Commission Marie Curie International Incoming Fellowship (FP7-PEOPLE-2012-IIF TANOGAPPs No. 326385) for generous support of this project.

\section{Notes and references}

1 D. Q. Yuan, W. G. Lu, D. Zhao and H.-C. Zhou, Adv. Mater., 2011, 23, 3723 .

2 (a) J.-X. Jiang, A. Trewin, F. B. Su, C. D. Wood, H. J. Niu, J. T. A. Jones, Y. Z. Khimyak and A. I. Cooper, Macromolecules, 2009, 42, 2658; (b) F. Vilela, K. Zhang and M. Antonietti, Energy Environ. Sci., 2012, 5, 7819; (c) Y. Xu, S. Jin, H. Xu, A. Nagai and D. Jiang, Chem. Soc. Rev., 2013, 42, 8012.

3 (a) J. Weber and A. Thomas, J. Am. Chem. Soc., 2008, 130, 6334; (b) L. Chen, Y. Honsho, S. Seki and D. Jiang, J. Am. Chem. Soc., 2010, 132, 6742; (c) D. B. Xiao, Y. Li, L. L. Liu, B. Wen, Z. J. Gu, C. Zhang and Y. S. Zhao, Chem. Commun., 2012, 48, 9519; (d) Y. H. Xu, A. Nagai and D. L. Jiang, Chem. Commun., 2013, 49, 1591.
4 (a) J. Jiang, F. Su, A. Trewin, C. D. Wood, N. L. Campbell, H. Niu, C. Dickinson, A. Y. Ganin, M. J. Rosseinsky, Y. Z. Khimyak and A. I. Cooper, Angew. Chem., Int. Ed., 2007, 46, 8574; (b) J.-X. Jiang, F. Su, A. Trewin, C. D. Wood, H. Niu, J. T. A. Jones, Y. Z. Khimyak and A. I. Cooper, J. Am. Chem. Soc., 2008, 130, 7710; (c) R. Dawson, A. Laybourn, R. Clowes, Y. Z. Khimyak, D. J. Adams and A. I. Cooper, Macromolecules, 2009, 42, 8809; (d) Q. Chen, M. Luo, T. Wang, J.-X. Wang, D. Zhou, Y. Han, C.-S. Zhang, C.-G. Yan and B.-H. Han, Macromolecules, 2011, 44, 5573.

5 (a) J. Schmidt, M. Werner and A. Thomas, Macromolecules, 2009, 42, 4426; (b) K. Zhang, B. Tieke, J. C. Forgie and P. J. Skabara, Macromol. Rapid Commun., 2009, 30, 1834.

6 (a) M. G. Schw, B. Fassbender, H. W. Spiess, A. Thomas, X. L. Feng and K. Müllen, J. Am. Chem. Soc., 2009, 131, 7216; (b) G. Y. Li, B. Zhang, J. Yan and Z. G. Wang, Chem. Commun., 2014, 50, 1897.

7 (a) R. Palkovits, M. Antonietti, P. Kuhn, A. Thomas and F. Schüth, Angew. Chem., 2009, 121, 7042; (b) S. J. Ren, M. J. Bojdys, R. Dawson, A. Laybourn, Y. Z. Khimyak, D. J. Adams and A. I. Cooper, Adv. Mater., 2012, 24, 2357; (c) X. Zhu, C. Tian, S. M. Mahurin, S. H. Chai, C. M. Wang, S. Brown, G. M. Veith, H. M. Luo, H. L. Liu and S. Dai, J. Am. Chem. Soc., 2012, 134, 10478.

8 (a) J. Schmidt, J. Weber, J. D. Epping, M. Antonietti and A. Thomas, Adv. Mater., 2009, 21, 702; (b) Y. L. Luo, B. Y. Li, W. Wang, K. B. Wu and B. E. Tan, Adv. Mater., 2012, 24, 5703.

9 Z. C. Shao, P. Rannou, S. Sadki, N. Fey, D. M. Lindsay and C. F. J. Faul, Chem. - Eur. J., 2011, 17, 12512.

10 J. Germain, F. Svec and J. M. J. Fréchet, Chem. Mater., 2008, 20, 7069.

11 A. Moissett, R. F. Lobo, H. Vezin, K. A. Al-Majnouni and C. Brémard, J. Phys. Chem. C, 2010, 114, 10280.

12 P. Kuhn, A. Forget, D. S. Su, A. Thomas and M. Antonietti, J. Am. Chem. Soc., 2008, 130, 13333.

13 J. Jeromenok and J. Weber, Langmuir, 2013, 29, 12982.

14 (a) D. Lozano-Castelló, D. Cazorla-Amorós and A. Linares-Solano, Carbon, 2004, 42, 1233; (b) N. Ritter, I. Senkovska, S. Kaskel and J. Weber, Macromolecules, 2011, 44, 2025.

15 P. I. Ravikovitch, A. Vishnyakov, R. Russo and A. V. Neimark, Langmuir, 2000, 16, 2311.

16 K. Tanaka, M. Okano, H. Toshino, H. Kita and K.-I. Okamoto, J. Polym. Sci., Part B: Polym. Phys., 1992, 30, 907.

17 (a) R. Dawson, E. Stöckel, J. R. Holst, D. J. Adams and A. I. Cooper, Energy Environ. Sci., 2011, 4, 4239; (b) Q. Chen, M. Luo, P. Hammershøj, D. Zhou, Y. Han, B. W. Laursen, C.-G. Yan and B.-H. Han, J. Am. Chem. Soc., 2012, 134, 6084. 